\title{
BN-183B, A NEW ANTITUMOR ANTIBIOTIC PRODUCED BY PSEUDOMONAS \\ TAXONOMY, ISOLATION, PHYSICO-CHEMICAL AND BIOLOGICAL PROPERTIES
}

\author{
Norio Ezaki, Shinji Miyadoh, Takashi Hisamatsu, Takao Kasai \\ and YUJiRo YAMADA \\ Central Research Laboratories, Meiji Seika Kaisha, Ltd., \\ Morooka-cho, Kohoku-ku, Yokohama 222, Japan \\ (Received for publication October 17, 1979)
}

\begin{abstract}
$\mathrm{BN}-183 \mathrm{~B}$ is a new antitumor antibiotic with chlorine in its molecule found in the culture broth of Pseudomonas sp. BN-183. The compound was weakly basic and isolated as a hydrochloride in a pure state. The molecular formula of its free base was determined as $\mathrm{C}_{14} \mathrm{H}_{20}$ $\mathrm{N}_{2} \mathrm{O}_{6} \mathrm{Cl}_{2}$. The antibiotic showed not only strong antimicrobial activity against both Grampositive and Gram-negative bacteria but also marked activity toward experimental tumors such as lymphoid leukemia L-1210 and lymphocytic leukemia P-388 in mice. No mutagenicity of $\mathrm{BN}-183 \mathrm{~B}$ was noted.
\end{abstract}

In the course of our screening program for new antibiotics from bacteria, we isolated a strain designated BN-183 which produced an antibiotic active against both Gram-positive and Gram-negative bacteria.

The novel antibiotic which was named BN-183B was found to be a weakly basic compound containing chlorine in its molecule. Besides excellent antimicrobial activities, the substance exhibited marked activity against experimental tumors of lymphoid leukemia L-1210 and lymphocytic leukemia P-388 in mice.

In this paper, we report taxonomic studies on strain BN-183, fermentation, isolation, physicochemical and biological properties of $\mathrm{BN}-183 \mathrm{~B}$.

\section{Taxonomic Studies of Strain BN-183}

The producing microorganism, strain $\mathrm{BN}-183$, was isolated from a soil sample collected at Tokai district of Ibaragi prefecture in Japan.

Strain BN-183 is a non-sporulating Gram-negative rod of $0.6 \sim 0.8$ by $1.0 \sim 2.0 \mu$ in size and is motile with polar flagella. Poly- $\beta$-hydroxybutyrate granules are observed by a phase contrast microscope. No sheath, stalk or slime is produced. The electromicrograph of strain BN-183 is shown in Fig. 1.

Physiological and biological properties of strain BN-183 are summarized in Tables 1 and 2 . According to BeRgeY's Manual of Determinative Bacteriology ${ }^{1)}$ and the observation reported by STANIER et al. ${ }^{2}$, the following conclusions have been made.

Strain BN-183 appears to belong to the genus Pseudomonas in view of the morphological, physiological and biological characteristics described above.

Strain BN-183 is considered to belong to Section II of genus Pseudomonas because it requires no growth factors, accumulates poly- $\beta$-hydroxybutyrate and uses arginine or betain as sole carbon source. 
The results of Tables 1 and 2 show that strain BN-183 closely resembles the species Pseudomonas cepacia and Pseudomonas marginata, but differs from these two with respect to the utilization of several carbon sources.

Thus strain $\mathrm{BN}-183$ has been conventionally named Pseudomonas sp. BN-183 and deposited in the Fermentation Research Institute, Agency of Industrial Science and Technology of Japan, under the accession number of FERM-P No. 3332 .

\section{Fermentation and Isolation of $\mathrm{BN}-183 \mathrm{~B}$}

As the result of preliminary medium test for fermentation of BN-183B, a combination of glycerin and dextrin as carbon source and soybean meal as nitrogen source produced a tolerable level of potency. Addition of sodium chloride or potassium chloride was indispensable for furnishing broths of high potency. The

Table 1. Physiological properties of strain BN-183.

\begin{tabular}{l|c}
\hline \multicolumn{1}{c|}{ Test } & Response \\
\hline $\begin{array}{l}\text { Growth in anaerobic conditions } \\
\text { Denitrification }\end{array}$ & - \\
Production of diffusible pigments & - \\
Hydrolysis of starch & - \\
$\begin{array}{l}\text { Accumulation of poly- } \beta \text {-hydroxy- } \\
\text { butyrate }\end{array}$ & + \\
Levan formation from sucrose & - \\
Decomposition of arginine & - \\
$\quad$ Mgg yolk reaction & - \\
Oxdase test & \\
Growth at $41^{\circ} \mathrm{C}$ & - \\
Requirement of growth factors & - \\
Liquefaction of gelatin & + \\
\hline
\end{tabular}

The scores of,+- and \pm represent positive, negative and faintly positive, respectively.
Fig. 1. Electron microscopic photograph of strain BN-183.

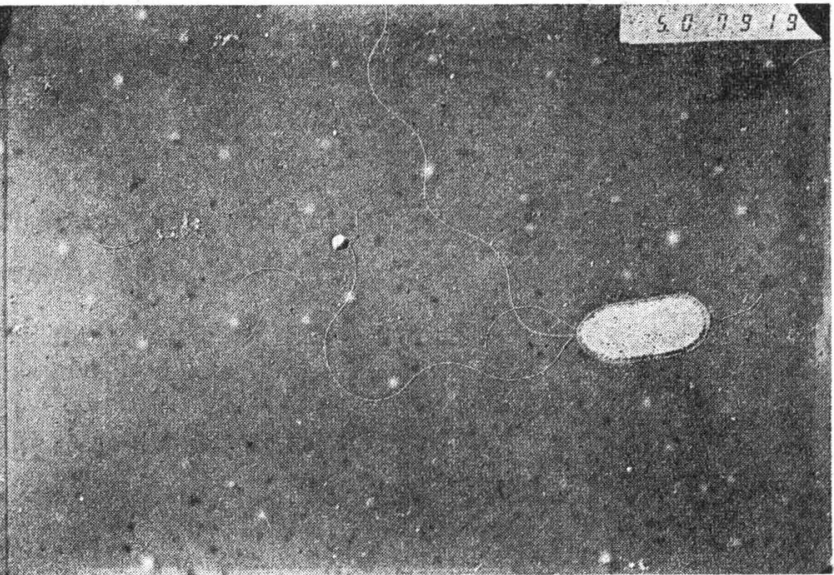

Table 2. Utilization of various carbon sources of strain BN-183.

\begin{tabular}{|c|c|c|c|}
\hline Carbon sources & $\begin{array}{l}\text { BN- } \\
183\end{array}$ & $\begin{array}{c}P . \\
\text { cepacia* }\end{array}$ & $\begin{array}{c}P . \\
\text { mar- } \\
\text { ginata* }\end{array}$ \\
\hline Glucose & + & + & + \\
\hline D-Xylose & + & \pm & + \\
\hline D-Fucose & + & + & + \\
\hline D-Arabinose & + & + & + \\
\hline D-Ribose & & + & + \\
\hline Cellobiose & + & + & + \\
\hline Saccharate & + & + & + \\
\hline L-Rhamnose & - & \pm & - \\
\hline Levulinate & + & + & - \\
\hline Citraconate & + & + & + \\
\hline Sebacate & + & + & + \\
\hline Mesaconate & - & - & + \\
\hline $\mathrm{D}(-)$ Tartarate & - & - & + \\
\hline meso-Tartarate & + & + & + \\
\hline$o$-Hydroxybenzoate & - & + & - \\
\hline$m$-Hydroxybenzoate & - & + & - \\
\hline Erythritol & - & - & - \\
\hline Adonitol & - & + & $\dot{i}$ \\
\hline 2,3-Butyleneglycol & - & + & - \\
\hline Betain & + & + & + \\
\hline Threonine & + & + & + \\
\hline Histidine & + & + & + \\
\hline Arginine & + & + & + \\
\hline Tryptamine & - & & - \\
\hline Ethanolamine & + & + & + \\
\hline Nicotinate & - & - & + \\
\hline Acetamide & - & t & - \\
\hline Anthranilate & - & + & \pm \\
\hline
\end{tabular}

The scores of,+- and \pm mean the same in Table 1.

* Data from R. W. Ballard et al. ${ }^{4)}$ 
maximum activity against Bacillus subtilis ATCC 6633 was obtained around fortyeight hours in cultivation of Pseudomonas sp. BN-183. The typical example of time course of fermentation is illustrated in Fig. 2.

Isolation of $\mathrm{BN}-183 \mathrm{~B}$ in a pure state was a rather difficult task owing to its weak basic nature which behaved ambiguously on the tests of resins and absorbents. BN-183B was absorbed on Diaion HP-20, and eluted with aqueous methanol. After removal of methanol, the active fraction was absorbed on CM-Sephadex C-25 column. The active fractions eluted with sodium chloride solution were desalted by the procedures with Diaion HP-20 mentioned above.
Fig. 2. Time course of BN-183B production in 300liter fermentor.

Concentration of glycerin was determined by the method of IWAI et $a l .^{3)}$
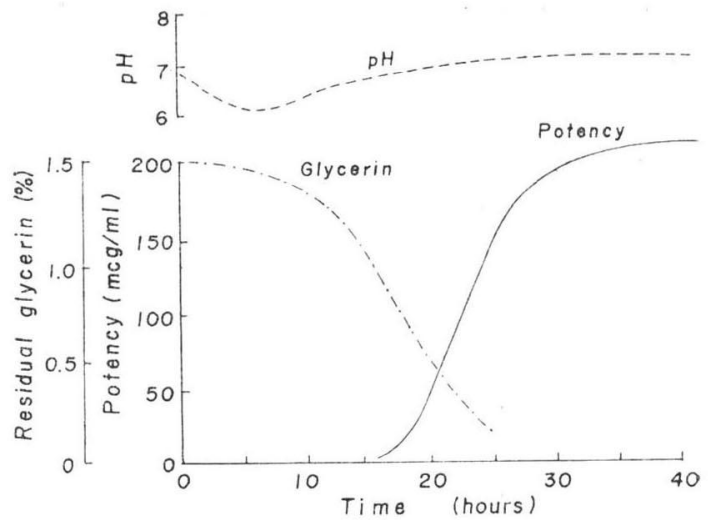

The resulting solution was concentrated under reduced pressure to furnish a partially purified powder. Further purification of BN-183B was performed by an extraction with methanol and the successive column chromatographies with active charcoal and DEAE-Sepharose CL-6B by developing both with water. The purified dry material was dissolved in methanol and concentrated under reduced pressure until precipitation of $\mathrm{BN}-183 \mathrm{~B}$ resulted. The condensate was kept at $5^{\circ} \mathrm{C}$ overnight and the precipitates were collected by filtration. The colorless powder of BN-183B hydrochloride was obtained in a pure state.

\section{Physico-chemical Properties of BN-183B}

$\mathrm{BN}-183 \mathrm{~B}$, isolated as the hydrochloride salt, is an amorphous and colorless powder. $\mathrm{BN}-183 \mathrm{~B}$ hydrochloride is soluble in water, methanol and sparingly soluble in ethanol, but very insoluble in acetone, benzene and hexane. The hydrochloride did not show a melting point and decomposed at $214^{\circ} \mathrm{C}$. The specific rotation of $\mathrm{BN}$ 183B hydrochloride was $[\alpha]_{\mathrm{D}}^{22}-9.2^{\circ}\left(c 1, \mathrm{H}_{2} \mathrm{O}\right)$.

The molecular formula of $\mathrm{BN}-183 \mathrm{~B}$ free base was determined as $\mathrm{C}_{14} \mathrm{H}_{20} \mathrm{~N}_{2} \mathrm{O}_{6} \mathrm{Cl}_{2}$ on the basis of the mass spectrum and elemental analysis of mono-N-acetyl BN-183B which was obtained as crystalline by treatment of $\mathrm{BN}-183 \mathrm{~B}$ with acetic anhydride in methanol. The molecular ion peak of mono-N-acetyl BN-183B was observed at $m / e$ 424. Elemental analysis of BN183B hydrochloride; Found: C 39.84; H 5.25; $\mathrm{N}$ 6.34; $\mathrm{Cl}$ 22.90. Anal. calcd. for $\mathrm{C}_{14} \mathrm{H}_{20} \mathrm{~N}_{2} \mathrm{O}_{6}$ $\mathrm{Cl}_{2} \cdot \mathrm{HCl}$ : C 40.05; H 5.01; N 6.67; Cl 25.39.
Fig. 3. Ultraviolet spectra of BN-183B hydrochloride.

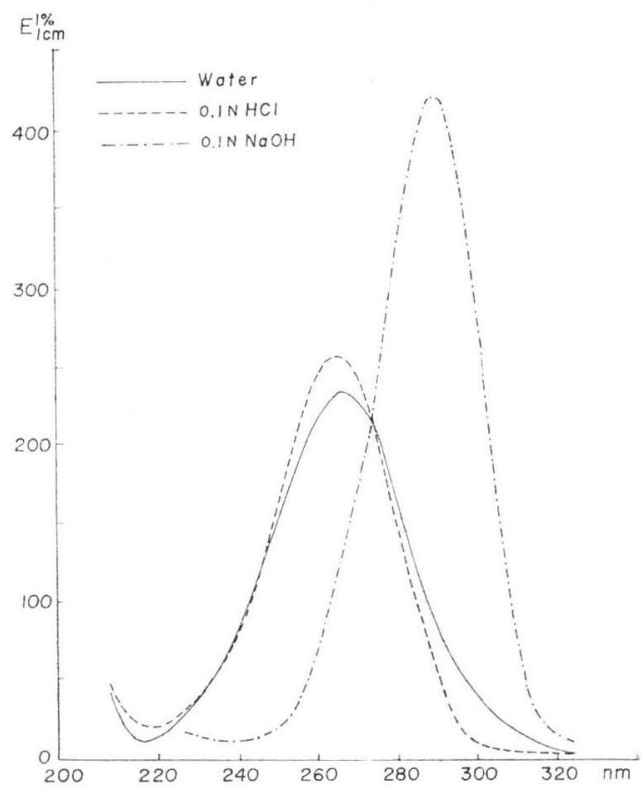


Elemental analysis of mono-N-acetyl BN-183B; Found: C 44.99; H 5.10; N 6.84; Cl 16.27. Anal. calcd. for $\mathrm{C}_{16} \mathrm{H}_{22} \mathrm{~N}_{2} \mathrm{O}_{7} \mathrm{Cl}_{2}$ : C 45.18; $\mathrm{H} 5.18 ; \mathrm{N} \mathrm{6.59;} \mathrm{Cl} 16.71$.

The BN-183B hydrochloride showed a UV maximal absorption at $264 \mathrm{~nm}\left(\mathrm{E}_{1 \mathrm{~cm}}^{1 \%} 258\right)$ in water, at $264 \mathrm{~nm}\left(\mathrm{E}_{1 \mathrm{em}}^{1 \%} 253\right)$ in $0.1 \mathrm{~N}$ hydrochloric acid and at $288 \mathrm{~nm}\left(\mathrm{E}_{\mathrm{cem}}^{1 \%} 413\right)$ in $0.1 \mathrm{~N}$ sodium hydroxide as illustrated in Fig. 3. The IR and PMR spectra are illustrated in Figs. 4 and 5, respectively.

The chromatographic mobility of $\mathrm{BN}-183 \mathrm{~B}$ hydrochloride by using silica gel thin-layer plate $\left(60 \mathrm{~F}_{254}\right.$, E. Merck) is shown in Table 3. The antibiotic was positive in ninhydrin and ferric chloride reaction, and negative in biuret reaction.

Fig. 4. Infrared spectrum of $\mathrm{BN}-183 \mathrm{~B}$ hydrochloride in $\mathrm{KBr}$.

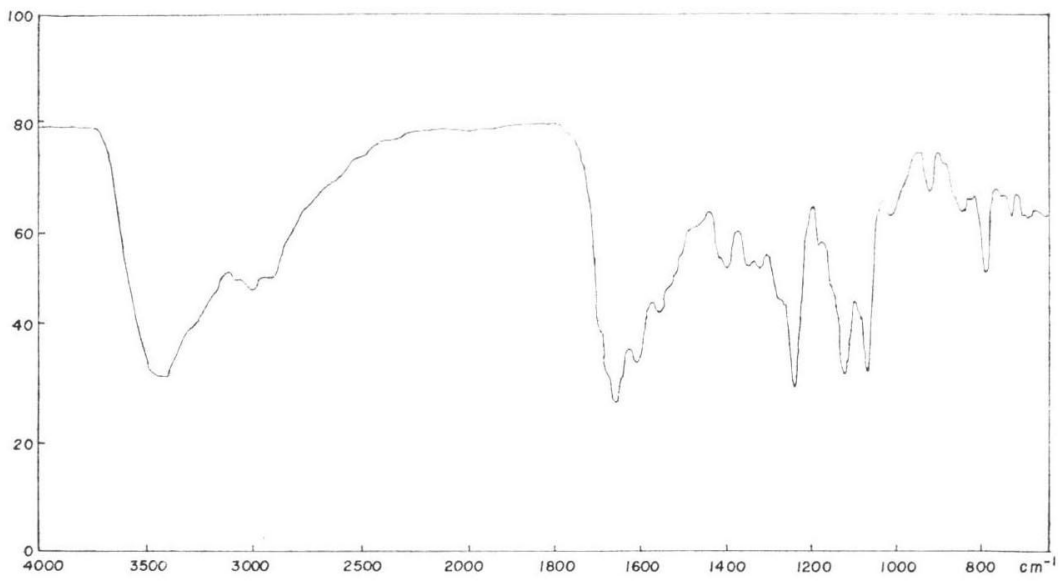

Fig. 5. $60 \mathrm{MHz}$ PMR spectrum of $\mathrm{BN}-183 \mathrm{~B}$ hydrochloride in $\mathrm{D}_{2} \mathrm{O}$.

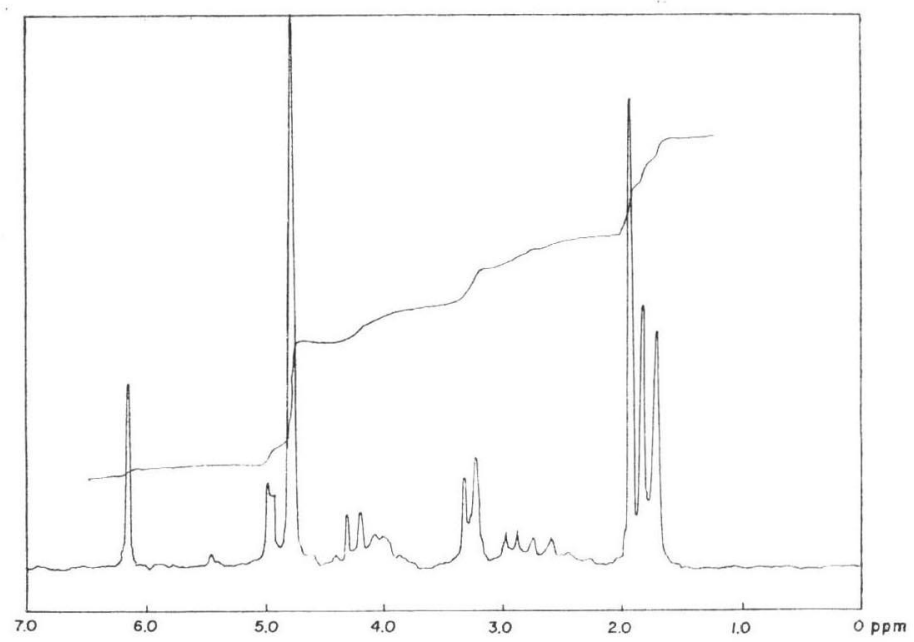

Antimicrobial Activity of BN-183B

The minimum inhibitory concentrations (MIC) of BN-183B hydrochloride against nineteen strains of eight genera of bacteria were determined by a two fold serial dilution method in agar, according to the standard methods recommended by the Japan Society of Chemotherapy ${ }^{5}$. 
Table 3. Chromatographic mobility of BN-183B hydrochloride.

\begin{tabular}{c|c}
\hline \multicolumn{1}{c|}{ Solvent system } & Rf value \\
\hline $\mathrm{BuOH}-\mathrm{AcOH}-\mathrm{H}_{2} \mathrm{O}(2: 1: 1)$ & 0.66 \\
$\mathrm{AcOEt}-\mathrm{AcOH}-\mathrm{H}_{2} \mathrm{O}(60: 17: 17)$ & 0.34 \\
$\mathrm{BuOH}-\mathrm{Pyridine}-\mathrm{AcOH}-\mathrm{H}_{2} \mathrm{O}$ & 0.65 \\
$(6: 4: 1: 3)$ & \\
\hline
\end{tabular}

Detection was made by ninhydrin reaction and bioautography with agar plate of Bacillus subtilis ATCC 6633.

As shown in Table 4, BN-183B hydrochloride was found to possess fairly strong antimicrobial activities toward both Gram-positive and Gram-negative bacteria. In another test of paper-disc agar-diffusion method using a concentration range of $100 \mathrm{mcg} / \mathrm{ml}$ to $1,000 \mathrm{mcg} / \mathrm{ml}$, this compound showed clear inhibitory zones against not only Pseudomonas aeruginosa 8151, Pseudomonas cepacia 8241 (both clinical strain) and Mycobacterium smegmatis ATCC 607 but also Candida albicans IAM 4888. Thus BN-183B appears to be one of the prominent antibiotics produced by bacteria with broad antimicrobial spectrum.

$\mathrm{LD}_{50}$ values of $\mathrm{BN}-183 \mathrm{~B}$ hydrochloride were determined by varied administration routes, i.e. oral (po), intravenous (iv), intramuscular (im), intraperitoneal (ip) and subcutaneous (sc) routes, and the results were tabulated in Table 5. BN183B appears to be a compound possessing comparatively high acute toxicity.
Table 4. MIC values of $\mathrm{BN}-183 \mathrm{~B}$.

\begin{tabular}{|c|c|}
\hline Test organisms & $\begin{array}{c}\mathrm{MIC} \\
(\mathrm{mcg} / \mathrm{ml})\end{array}$ \\
\hline $\begin{array}{l}\text { Staphylococcus aureus Rosenbach } \\
\text { FDA 209P JC-1 }\end{array}$ & 0.39 \\
\hline Staphylococcus aureus Smith S-424 & 0.39 \\
\hline Staphylococcus aureus No. 26* & 0.78 \\
\hline Staphylococcus aureus N-0032* & 0.78 \\
\hline $\begin{array}{l}\text { Staphylococcus epidermidis } \\
\text { ATCC } 14990\end{array}$ & 0.39 \\
\hline Staphylococcus epidermidis N-0028* & 0.10 \\
\hline Streptococcus faecalis ATCC 8043 & 0.10 \\
\hline Bacillus anthracis No. 119 & 12.5 \\
\hline Bacillus subtilis PCI 219 & 0.10 \\
\hline $\begin{array}{l}\text { Escherichia coli Cast. \& Chalm. } \\
\text { NIHJ JC-2 }\end{array}$ & 3.13 \\
\hline Escherichia coli $\mathrm{K}-12$ IAM 1264 & 3.13 \\
\hline Escherichia coli W677 (A-20684)* & 1.56 \\
\hline $\begin{array}{l}\text { Escherichia coli JR 66/W } 677 \\
\text { (A-20683)* }\end{array}$ & 1.56 \\
\hline Salmonella typhi 0-901-W & 6.25 \\
\hline Shigella dysenteriae Shigae & 1.56 \\
\hline Klebsiella pneumoniae PCI 602 & 25 \\
\hline $\begin{array}{l}\text { Klebsiella pneumoniae } 22 \$ 3038 \\
\text { (A-20680) }\end{array}$ & 12.5 \\
\hline $\begin{array}{l}\text { Klebsiella pneumoniae CN } 69 \\
\text { (PCase: H) }\end{array}$ & 12.5 \\
\hline Proteus vulgaris OX 19 & 12.5 \\
\hline
\end{tabular}

* Clinical isolates.

Table 5. $\mathrm{LD}_{50}$ values of $\mathrm{BN}-183 \mathrm{~B}$ hydrochloride by varied administration routes.

\begin{tabular}{c|c|c|c|c|c}
\hline Route & po & iv & im & ip & sc \\
\hline $\mathrm{LD}_{50}(\mathrm{mg} / \mathrm{kg})$ & 50.0 & 4.1 & 4.1 & 4.3 & 6.0 \\
\hline
\end{tabular}

Ten JCL-ICR mice weighing $20 \pm 0.5 \mathrm{~g}$ were used for each administration route.

\section{Antitumor Activity of BN-183B}

The effect of BN-183B hydrochloride on lymphoid leukemia L-1210 and lymphocytic leukemia P-388 was investigated, and the results were summarized in Table 6.

Seventy one percent and 92\% increase in life span against L-1210 and P-388 were observed respectively at an optimal effective dose, $4 \mathrm{mg} / \mathrm{kg}$, in the administration schedule of day $1 \sim 3$ (intraperitoneal injection for 3 consecutive days) as compared to their respective untreated control. However, no animal survived for more than twenty days through the experiment. At a higher dose, $6 \mathrm{mg} / \mathrm{kg}$, no effectiveness was found against both tumors. This appears to be due to the acute toxicity of the substance. 


\section{Mutagenicity of BN-183B}

The mutagenicity of $\mathrm{BN}-183 \mathrm{~B}$ hydrochloride was examined by in vitro microbial test ${ }^{6}$ ) known as the AmEs' test. The strains Escherichia $\operatorname{coli}(\mathrm{B} / \mathrm{r}) \mathrm{WP}^{6)}$ and Salmonella typhimurium ${ }^{7,8)}$ were all kindly supplied from Dr. T. KADA, National Institute of Genetics, Mishima.

As shown in Table 7, BN-183B hydrochloride did not demonstrate any mutagenic activity toward all strains tested, whereas two carcinogenic agents as positive control, 4-nitro-quinoline-N-oxide (4-NQO) and N-methyl-N-nitro$\mathrm{N}^{\prime}$-nitrosoguanidine (NTG) were both clearly positive in the revertant forming test.

Considering the biological properties described above, BN-183B appears to be characterized by its antitumor activities lacking mutagenicity rather than its antimicrobial activities. Thus, this substance is probably the first antitumor antibiotic found of bacterial origin.
Table 6. Effect of $\mathrm{BN}-183 \mathrm{~B}$ by intraperitoneal injection on L-1210 and P-388.

\begin{tabular}{|c|c|c|c|}
\hline Tumor & $\begin{array}{l}\text { Dose }^{*} \\
(\mathrm{mg} / \mathrm{kg})\end{array}$ & $\begin{array}{l}\text { Survival days } \\
(\mathrm{T} / \mathrm{C})^{* *}\end{array}$ & $\begin{array}{c}\operatorname{ILS}_{(\% * *} * \\
(\%)\end{array}$ \\
\hline \multirow{6}{*}{$\begin{array}{l}\mathrm{L}-1210 \\
10^{6} \text { cell (ip) } \\
\left(\mathrm{BDF}_{1}\right)\end{array}$} & 6 & $3.2 / 7.6$ & -57.9 \\
\hline & 4 & $13.0 / 7.6$ & 71.0 \\
\hline & 2 & $12.2 / 7.6$ & 60.5 \\
\hline & 1 & $11.0 / 7.6$ & 44.7 \\
\hline & 0.5 & $10.2 / 7.6$ & 34.2 \\
\hline & 0.25 & $9.4 / 7.6$ & 23.7 \\
\hline \multirow{7}{*}{$\begin{array}{l}\text { P-388, } \\
10^{6} \text { cell (ip) } \\
\left(\mathrm{CDF}_{1}\right)\end{array}$} & 6 & $7.0 / 10.3$ & -32.0 \\
\hline & 4 & $19.8 / 10.3$ & 92.2 \\
\hline & 2 & $17.2 / 10.3$ & 67.0 \\
\hline & 1 & $15.6 / 10.3$ & 51.5 \\
\hline & 0.5 & $14.4 / 10.3$ & 39.8 \\
\hline & 0.25 & $14.0 / 10.3$ & 35.9 \\
\hline & 0.125 & $11.0 / 10.3$ & 6.8 \\
\hline
\end{tabular}

Five males of $\mathrm{BDF}_{1}$ hybrid and $\mathrm{CDF}_{1}$ hybrid mice weighing $21 \pm 1 \mathrm{~g}$ were used in each administrated dose. One million cell of L-1210 or P-388 were intraperitoneally transplanted into mice.

* Intraperitoneal injection of BN-183B hydro. chloride was begun at 24 hours after the transplantation and performed once a day for 3 days.

** $\mathrm{T} / \mathrm{C}=$ treated/control

*** Increase in life span.

Table 7. Results of AmEs' test of BN-183B hydrochloride.

\begin{tabular}{|c|c|c|c|c|c|c|c|c|c|}
\hline \multirow{3}{*}{ Test compounds } & \multirow{3}{*}{$\begin{array}{l}\text { Concentration } \\
(\mathrm{mcg} / \mathrm{ml})\end{array}$} & \multicolumn{8}{|c|}{ Strains } \\
\hline & & \multicolumn{2}{|c|}{ E. coli } & \multicolumn{6}{|c|}{ S. typhimurium } \\
\hline & & $\mathrm{her}^{+}$ & her $^{-}$ & TA 1535 & TA1536 & TA 1537 & TA 1538 & TA98 & TA 100 \\
\hline \multirow{3}{*}{$\begin{array}{l}\text { BN-183B hydro- } \\
\text { chloride }\end{array}$} & 10,000 & - & - & - & - & - & - & - & - \\
\hline & 1,000 & - & - & - & - & - & - & - & - \\
\hline & 100 & - & - & -- & - & - & - & - & \\
\hline $4 \mathrm{NQO}$ & 100 & & + & + & - & - & $+t$ & $+t$ & $+t+$ \\
\hline NTG & 1,000 & $+t$ & & $+t+$ & - & - & - & $+t$ & ++4 \\
\hline
\end{tabular}

A paper disc of $8 \mathrm{~mm}$ diameter containing $20 \mu \mathrm{l}$ of each sample was placed on the center of each agar plate and incubated at $37^{\circ} \mathrm{C}$ for 2 days. The revertant colonies formed around the paper disc were counted and scored as $+++:>100,++:>50,+:>20$ and $-:<20$.

\section{Experimental}

(1) Fermentation

Antimicrobial activity of BN-183B was investigated by a paper-disc agar-diffusion method using Bacillus subtilis ATCC 6633 as an assay organism. A 500-ml Erlenmeyer flask containing $100 \mathrm{ml}$ of a seed medium composed of $1 \%$ glycerine, $0.5 \%$ glucose, $1 \%$ Polypeptone, $0.5 \%$ meat extract and

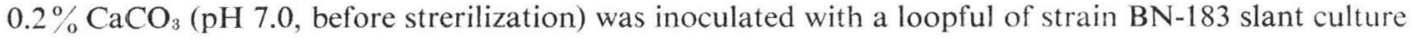


and incubated at $28^{\circ} \mathrm{C}$ for 2 days on a rotary shaker $(200 \mathrm{rpm})$. The first seed culture thus obtained was transferred into a 30-liter jar fermentor containing 20 liters of a medium consisted of $1.5 \%$ glycerin, $1.5 \%$ dextrin, $2 \%$ soybean meal, $0.5 \% \mathrm{KCl}$ and $0.2 \% \mathrm{CaCO}_{3}(\mathrm{pH} 6.8)$, and operated at $28{ }^{\circ} \mathrm{C}$ for 2 days using an agitation rate of $180 \mathrm{rpm}$ and an air flow rate of $0.5 \mathrm{vol} . / \mathrm{vol} . / \mathrm{min}$. During the cultivation Silicon KM 68-2F (Shin-etsu Kagaku Co., Tokyo) as antifoamer was automatically added. The production of $\mathrm{BN}-183 \mathrm{~B}$ was conducted in a 300-liter stainless steel fermentation vessel containing 200 liters of the above medium. One liter of the second seed culture mentioned above was transferred into the vessel and the fermentation was carried out at $28^{\circ} \mathrm{C}$ for two days with an agitation rate of $120 \mathrm{rpm}$ and an air flow rate of $0.5 \mathrm{vol} . / \mathrm{vol} . / \mathrm{min}$.

\section{(2) Isolation}

The culture broth (150 liters) having a titer of $200 \mathrm{mcg} / \mathrm{ml}$ of BN-183B was successively centrifuged. To the clarified supernatant ( $\mathrm{pH} 6.8$ ), Diaion HP-20 resin (15 liters) was added and the mixture was vigorously stirred for an hour. The separated adsorbent was packed in a column and washed with 30 liters of $50 \%$ methanol. Active fractions (90 liters), eluted with $80 \%$ methanol, were pooled, evaporated and diluted with water to make the volume 50 liters. The aqueous solution ( $\mathrm{pH} 7.0$ ) was passed through a column of CM-Sephadex C-25 (4.5 liters), and washed with deionized water (12 liters). The column was developed with $0.1 \mathrm{M}$ sodium chloride solution. The resulting active fractions (10 liters) was passed through a column of Diaion HP-20 resin (5 liters) and washed with deionized water ( 7.5 liters) and followed by an elution with $50 \%$ methanol. The active fractions (10 liters) collected were evaporated to dryness to give brownish powder $(4.1 \mathrm{~g}, 750 \mathrm{mcg} / \mathrm{mg})$. The material was then dissolved in methanol and filtered to remove the insoluble matter. The resulting clarified solution was applied onto a charcoal column $(100 \mathrm{ml})$ and the elution with methanol was performed. The resulting active fraction $(500 \mathrm{ml})$ was evaporated to dryness to furnish a yellowish powder $(3.3 \mathrm{~g}, 920 \mathrm{mcg} / \mathrm{mg})$. After dissolving with a small volume of water $(12 \mathrm{ml})$, the purified material was subjected to a column of DEAE-Sepharose CL-6B $(370 \mathrm{ml})$ and developed with water. The active fractions $(170 \mathrm{ml})$ were collected and evaporated to dryness to give pale yellowish powder $(3.0 \mathrm{~g})$ which showed a single spot on TLC (Table 3). The purified powder was dissolved in methanol $(150 \mathrm{ml})$ and concentrated until a precipitate began to come out. The mixture was kept in a refrigerator $\left(5^{\circ} \mathrm{C}\right)$ overnight. The resulting precipitates deposited were collected by filtration and dried under reduced pressure. The purified powder of BN-183B hydrochloride ( $2.5 \mathrm{~g}$ ) was obtained at the overall yield of 8.3 percent.

\section{Addendum}

After this manuscript was submitted, a paper on bactobolin was reported in J. Antibiotics 32: 1069 1071, 1979 by S. Kondo, Y. Horiuchi, M. Hamada, T. Takeuchi \& H. Umezawa. Our antibiotic seems to be identical with bactobolin. The similarity of both antibiotics will be reported elsewhere.

\section{Acknowledgements}

The authors wish to acknowledge the collaboration of the members of Pharmaceutical Development Laboratories of Meiji Seika Kaisha, Ltd. for large scale fermentations and furnishing crude samples.

\section{References}

1) Buchanan, R. E. \& N. E. Gibbons: Bergey`s Manual of Determinative Bacteriology. 8th ed., p. 217, The Williams \& Wilkins Co., Baltimore, 1974

2) Stanier, R. Y.; N. J. Palleroni \& M. Doudoroff: The aerobic pseudomonads: a taxonomic study. J. Gen. Microbiol. 43: 159 271, 1966

3) IWAi, Y.; S. Ömura \& T. Hata: The determination of glycerol in the broth of an antibiotic-producing fermentation culture of Streptomyces sp. J. Ferment. Technol. 49: 842 846, 1971

4) Ballard, R. W.; N. J. Palleroni, M. Doudoroff \& R. Y. Stanier: Taxonomy of the aerobic pseudomonads: Pseudonomas cepacia, P. marginata, P. alliicola and P. caryophylli. J. Gen. Microbiol. 60: 199 214,1970 
5) Japan Society of Chemotherapy: The revised method of determination of MIC value. Chemotherapy 22: $1126 \sim 1128,1974$

6) Shirasu, Y.; M. Moriya, K. Kato, A. Furuhashi \& T. Kada: Mutagenicity screening of pesticides. in the microbial system. Mutation Res. 40: 19 30, 1976

7) AmEs, B. N.; J. MCCANN \& E. YAMASAKI: Methods for detecting carcinogens and mutagens with the salmonella/mammalian-microsome mutagenicity test. Mutation Res. 31: $347 \sim 367,1975$

8) McCann, J.; N. E. Spingarn, J. Kobori \& B. N. Ames: Detection of carcinogenes as mutagens: Bacterial tester strains with R-factor plasmids. Proc. Nat. Acad. Sci., U.S.A. 72: 979 983, 1975 